patients, should share common aims. The view of the practice of medicine as team-work may be common, the thought that it extends to social workers, psychiatrists, receptionists, patients and the community, less so, However, the idea that common aims should be developed if the responsibilities of respect are to be met is one that may seem particularly apposite in the light of recent discussions centring around the Cleveland child abuse cases.

The book is not only aimed at a wide readership, it is also accessible. It is divided into two parts. The first provides an introduction to the field of medical-ethical debate while developing the notion of respect and clarifying and examining the implications of what might be meant by 'a person'. Respect for autonomy, it is argued, requires an attitude of compassion and the imagination to see a situation from eyes other than one's own. Compassion is active and distinguished from pity. Personhood, it is argued, could be something humans move into and out of. Alternative views of personhood are also offered giving the reader other perspectives than the book's, and providing help in treating with respect patients from different backgrounds or cultures. More could have been made of this. A chapter on arguments is provided at the end of the first section. This seems particularly useful. Much of normal life, let alone the medical life with its particular demands and dilemmas, requires capacities to analyse and weigh up arguments.

The second part deals with the practical issues and dilemmas of modern medicine and uses the skills and conclusions of the first. Here discussion, of abortion, for example, is situated in relation to discussion of contraception, artificial insemination, in vitro fertilisation, surplus embryos and surrogacy. A chapter on death and dying deals with questions of resuscitation, euthanasia, suicide, terminal diseases and the hospice movement. Topically, issues of community health, inequalities in health care, economics and limited resources are also discussed.

Healthy Respect is easy to follow and well designed for use by a lecturer with a group of students, as well as individuals. There are summaries of each chapter in the first part, and in the second part there are a series of questions and exercises which would help either an individual reader, or a group of students, to clarify their thinking on particular issues. References for further reading of various types are also given.

The bibliography includes some novels and poems, the thought being that such literature may throw up moral questions and questions about society. One could add that reading books may help that imaginative function necessary for respect - seeing from another's point of view. Healthy Respect deserves a wide audience and given its suitability as a teaching aid it should get one.

SARAH HADDON FURNESS Lecturer in Philosophy, and Fournalist, University of Essex

\section{Human Rights: from Rhetoric to Reality}

Tom Campbell, David Goldberg, Sheila McLean, Tom Mullen, editors, 262 pages, Oxford and New York, $£ 27.50$ hardcover, £9.95 paperback, Basil Blackwell, 1986

John Stuart Mill wrote 'the only freedom which deserves the name is that of pursuing our own good in our own way, so long as we do not attempt to deprive others of theirs, or impede their efforts to obtain it. Each is the proper guardian of his own health, whether bodily, or mental and spiritual'. This rhetoric of rights is taken up by the international declarations and treaties on human rights. Although English law does not talk in terms of rights, individuals, whether they are patients, trade unionists or protesters, inevitably revert to such language. These eleven essays examine, in various subject areas, the problems which arise in translating the ideas expressed in human rights into specific practical requirements. The image of human rights is, as Tom Campbell points out, 'morally compelling and attractively uncompromising'; practicality, the rights of others, restraints on the public purse and not least public opinion do, however, require compromise and each of the essays explores the reality or validity of a claimed right.

The International Bill of Rights divides rights, for the purposes, in the main, of implementation, into economic, social and cultural rights on one hand, and civil and political on the other. Any attempt to characterise a right as one or the other soon brings the realisation that this division is artificial and that, even in rhetorical terms,

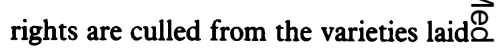
down in the international texts. Rights in the medical field, and three of the $\overline{\bar{D}}$. essays are devoted to these, seem to $s$ centre around an individual's 'right' to self-determination. Sheila McLean examines 'the right to reproduce' ando 'the right to consent to medicalo treatment'. Each of these raises, in its positive aspect, the position of the $\widetilde{\Phi}$ individual in the society of others and in the context of public expenditure; more fascinating, perhaps, is her enquiry into $\vec{\circ}$ the negative points - the right not to:reproduce and the right to refuse $\vec{\omega}$ consent to medical treatment. It is important to distinguish the components of consent so that the $\overparen{D}$ patient may refuse if he or she feels that $\vec{\omega}$ there are oiher factors which seem more $A$ important. Tom Campbell's second iv essay, on the rights of the mentally ill, $\vec{v}$ points out that freedom of individuality includes the right to eccentric behaviour which presumably will $\square$ extend to those with mental illness.

Other essays deal (inter alia) with $\frac{\Phi}{3}$ such topics as women's rights and those to membership of trade unions and to public assembly and procession. The $\vec{C}$ immense problem of deducing reality the case of each of these rights can $\overline{j e}$. seen. The reality of rights depends social, financial and politigg circumstances at any given time in any given country. While the rhetorical force of human rights is of 'uncertain $\frac{\mathrm{D}}{\mathrm{N}}$ practical significance', and needs $\varrho$ 'supplementation by more specific and $\overrightarrow{\overrightarrow{0}}$ informative formulations of policy 3 objectives' this group of thoughtprovoking and attractive essays makes a sensitive exploration into many of these troublesome questions.

RALPH BEDDARD Senior Lecturer, Faculty of Law, University of Southampton $\mathrm{O}$

\section{A History and Theory of Informed Consent}

R Faden, T L Beauchamp, 392 pages, Oxford, £27.50, Oxford University Press, 1986

The agenda for this book is both ${ }^{\mathcal{O}}$ considerable and well handled. The history of informed consent is set out in $\bar{\Phi}$ rich detail as it figures in medical $\stackrel{\text { ? }}{+}$ writings, legal theory and case law. The $\square$ complex relations between the battery $\bar{C}^{\circ}$ model and the autonomy model are carefully described.

The authors do however make the claim that the strand of autonomy was 